\title{
Plant-Arthropod Interactions: A Behavioral Approach
}

\author{
Kleber Del-Claro, ${ }^{1}$ Monique Johnson, ${ }^{2}$ and Helena Maura Torezan-Silingardi ${ }^{1}$ \\ ${ }^{1}$ Laboratório de Ecologia Comportamental e de Interações (LECI)., Instituto de Biologia, Universidade Federal de Uberlândia, \\ P.O. Box 593, 38400-902 Uberlândia, MG, Brazil \\ ${ }^{2}$ Laboratoire Ecologie et Biologie des Interactions UMR CNRS 7267, Équipe Ecologie, Evolution, Symbiose, Université de Poitiers, \\ 40 Avenue du Recteur Pineau, 86022 Poitiers Cedex, France
}

Correspondence should be addressed to Kleber Del-Claro, delclaro@ufu.br

Received 14 November 2012; Accepted 14 November 2012

Copyright ( $) 2012$ Kleber Del-Claro et al. This is an open access article distributed under the Creative Commons Attribution License, which permits unrestricted use, distribution, and reproduction in any medium, provided the original work is properly cited.

In a community, the species present may be linked directly or indirectly through resources and consumption. More than $90 \%$ of the fixed energy in terrestrial systems is processed autotrophically by plants and thus almost all terrestrial fauna depend on this production. Classically, in systems involving three trophic levels, such as plants, herbivores, and predators, a trophic cascade describes the positive top-down effects of the third trophic level on the biomass, richness, or composition of the producer species (see [1] and references therein).

In a more recent and realistic approach, biodiversity is viewed and evaluated in ways that embrace the extreme richness inherent in plant-animal interactions, including not only trophic relationships, but also aspects of life histories, biology, and behavior of interacting species [1]. The richness of biotic interactions has been identified as the main force responsible for the biodiversity that maintains viable communities. Indeed, the success of life on Earth is directly linked to the success of biotic interactions [2]. Biotic interactions are present everywhere, in air, water, soil, and on or inside organisms regardless of their size.

Among all of these interactions, those between plants and animals have been described as being largely responsible for the functioning and maintenance of trophic chains in ecosystems and also for the patterns and processes that structure biodiversity on Earth [3]. This idea was born of the hundreds of papers published in the last century, mainly between 1960 and 1990, involving mutualistic and antagonistic plant-animal relationships (Figure 1). In these studies, the outcomes of interactions were almost always related to aspects of the natural history of the interacting plant and/or animal species involved (e.g., [4, 5]). In addition, many of these studies revealed that the final interaction results often differed as a function of season and/or year, thus clearly demonstrating the importance of studying the natural history of interacting species in order to truly further our understanding of the existing interactions [6]. Also, the outcomes of interactions may vary as a function of the physical and biotic changes in the environment. Thus, there is no mutualistic relationship that will be always and unconditionally one of mutualism. Similarly, predatory or parasitic relationships may be subject to changes occurring more or less quickly over evolutionary time that can drive the results of the interaction in a different direction.

Although greatly recognized as relevant, basic knowledge concerning species interactions, including plant phenological variations, features of life histories, and animal behavior, is surprisingly rarely considered in the more recent studies of plant-animal network interactions [7]. In this special volume, we have selected papers in order to draw attention to these interaction network studies as they are fundamental to the comprehension of specialization patterns in plants and animals [8]. We have decided to center our attention on arthropod-plant relationships in this volume, mainly due to the entomological scope of the journal but also due to the fact that arthropod-plant interactions exhibit a wide variety of relationships. Readers will thus discover here a myriad of interaction possibilities in the different articles, from more general and theoretical studies to basic and natural history studies in arthropod-plant interactions. We hope that this special volume will both exemplify how these interactions 


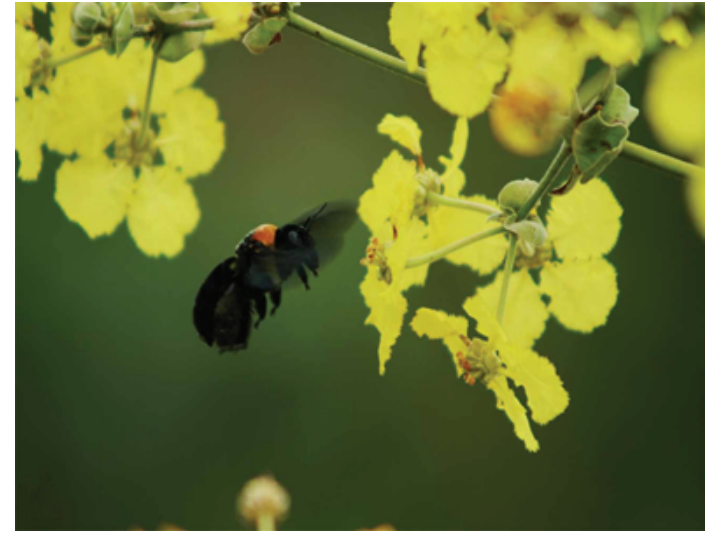

(a)

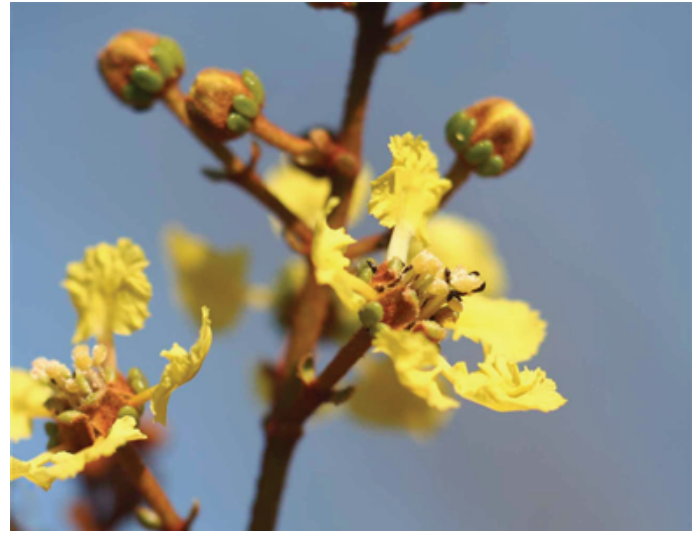

(b)

Figure 1: The Malpighiaceae (Peixotoa tomentosa) has its flowers visited by (a) the pollinator bee (Centris (Ptilotopus), Apidae) and (b) also (like in Banisteriopsis laevifolia) by the small black thrips (Heterothrips peixotoa, Heterothripidae) that infest and destroy its stamens and stigma.

can contribute to the general ecological theory and reinforce the value of natural history and behavioral studies.

\section{Kleber Del-Claro \\ Monique Johnson \\ Helena Maura Torezan-Silingardi}

\section{References}

[1] K. Del-Claro and H. M. Torezan-Silingardi, "Insect-plant interactions: new pathways to a better comprehension of ecological communities in Neotropical savannas," Neotropical Entomology, vol. 38, no. 2, pp. 159-164, 2009.

[2] N. Blüthgen, "Ecologia das interações Animais-Plantas: Interações Planta-Animais e a importância funcional da biodiversidade," in Ecologia das Interações Plantas-Animais: Uma Abordagem Evolutiva, K. Del-Claro and H. M. Torezan-Silingardi, Eds., pp. 261-272, Technical Books Editora, Rio de Janeiro, Brazil, 2012.

[3] J. N. Thompson, The Geographic Mosaic of Coevolution, University of Chicago Press, Chicago, Ill, USA, 2005.

[4] E. O. Wilson, Biodiversity, National Academy Press, Washington, DC, USA, 1988.

[5] H. M. Torezan-Silingardi, "Predatory behavior of Pachodynerus brevithomx (Hymenoptera: Vespidae, Eumeninae) on endophytic herbivore beetles in the Brazilian tropical savanna," Sociobiology, vol. 57, no. 1, pp. 181-189, 2011.

[6] K. Del-Claro and P. S. Oliveira, "Conditional outcomes in a neotropical treehopper-ant association: temporal and speciesspecific variation in ant protection and homopteran fecundity," Oecologia, vol. 124, no. 2, pp. 156-165, 2000.

[7] N. Blüthgen, "Why network analysis is often disconnected from community ecology: a critique and an ecologist's guide," Basic and Applied Ecology, vol. 11, no. 3, pp. 185-195, 2010.

[8] T. M. Lewinsohn, P. Inácio Prado, P. Jordano, J. Bascompte, and J. M. Olesen, "Structure in plant-animal interaction assemblages,” Oikos, vol. 113, no. 1, pp. 174-184, 2006. 

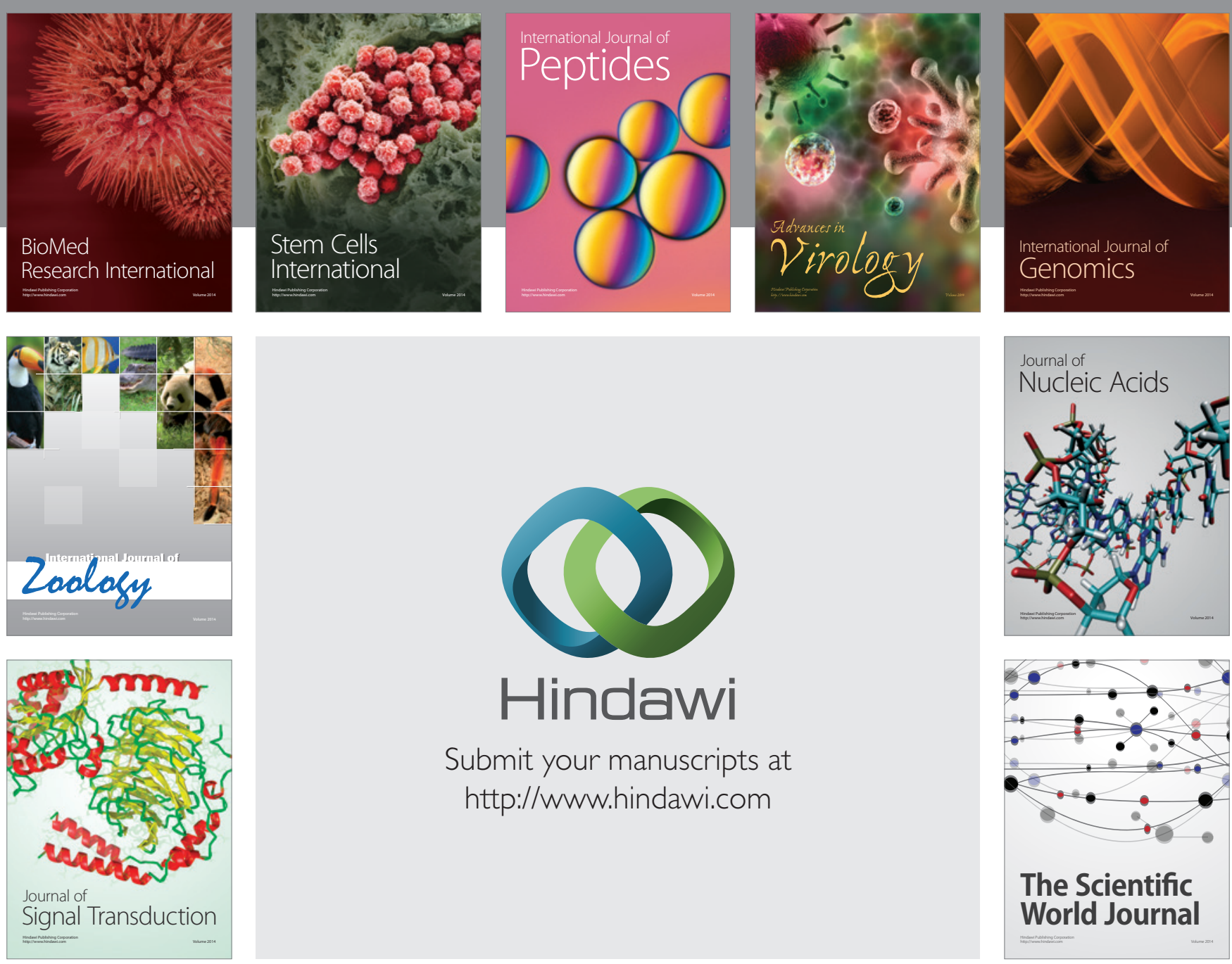

Submit your manuscripts at

http://www.hindawi.com
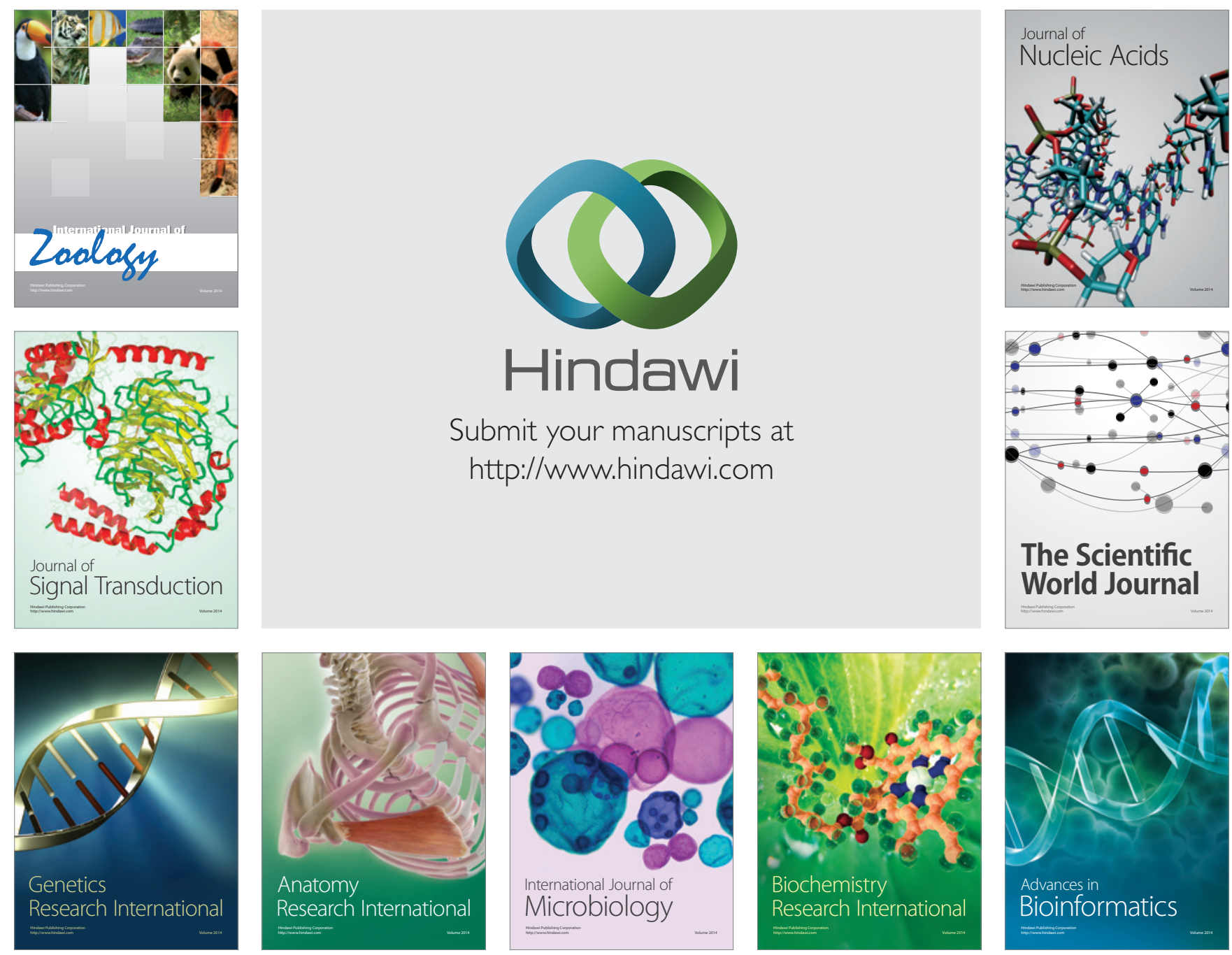

The Scientific World Journal
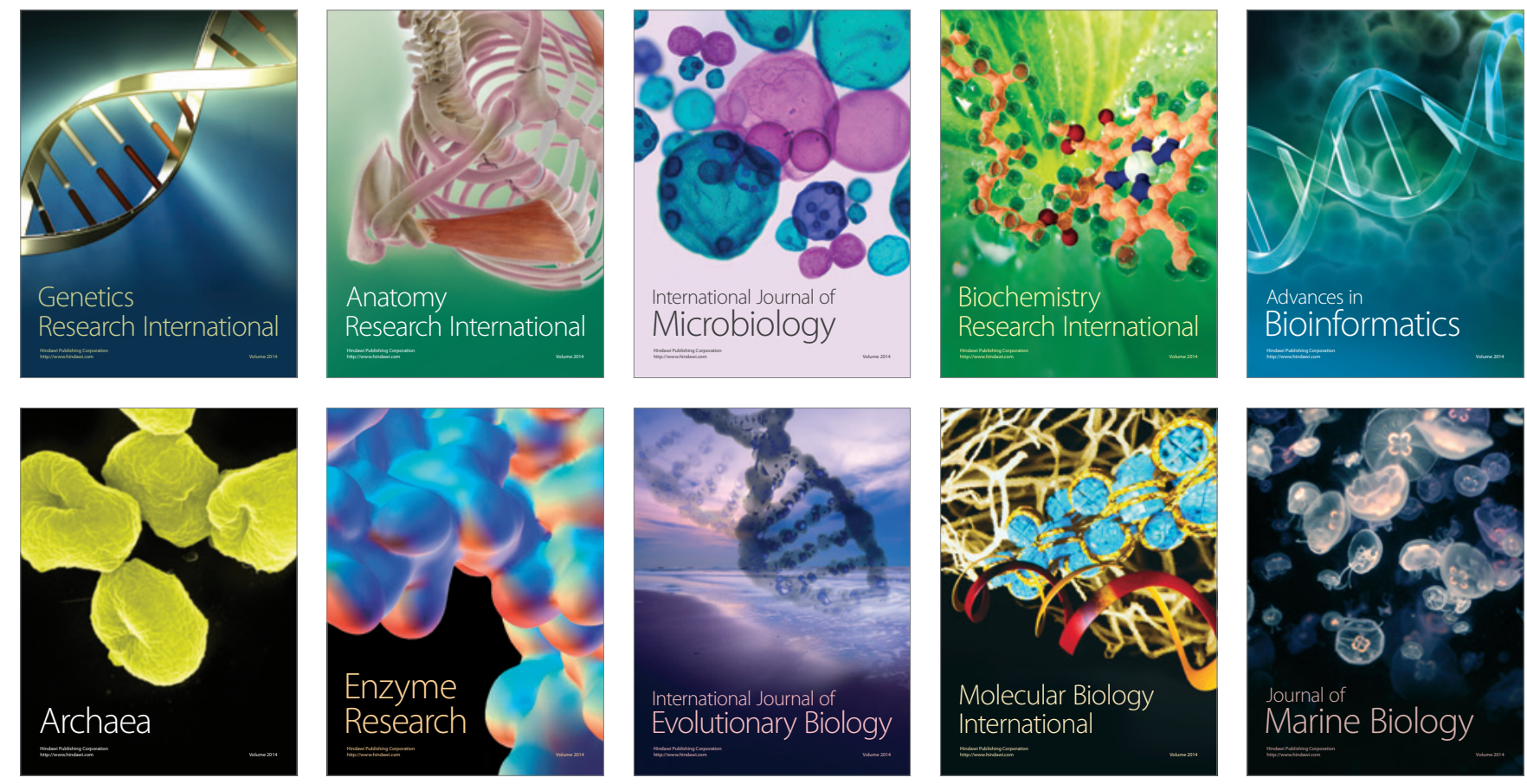